\title{
RÚSSIA ATUAL: PRODUTO DA HERANÇA BIZANTINA E DO ESPÍRITO TÉCNICO NORTE-AMERICANO*
}

\author{
Maurício Tragtenberg
}

\begin{abstract}
RESUMO: Este artigo desenvolve uma análise da Revolução Russa de 1917, a partir do exame de seu processo histórico de longa duração, no qual a implantação do cristianismo bizantino foi fundamental. $\mathrm{O}$ autor recorre à metáfora geológica da pseudo-morfose para explicar esse processo histórico e a ascensão do bolchevismo em 1917 e para estabelecer uma analogia entre os dois centros mundiais do poder durante parte do século XX.
\end{abstract}

Palavras-chave: Pseudo-morfose. Revolução Russa. Tecnicismo. Cristianismos. Norte- Americano.

\section{Present Russia: Product of BYZANTINe herITAGe AND OF THE NORTH-AMERICAN TECHNICAL SPIRIT}

\begin{abstract}
This paper analyzes the 1917 Russian Revolution, by examining its long-lasting historical process, in which the adoption of Byzantine Christianity played a key role. The author resorts to the geological metaphor of pseudomorphosis to explain this historical process, the rise of Bolshevism in 1917, and to establish an analogy between the two worldwide centers of power during part of $20^{\text {th }}$ century.
\end{abstract}

Key words: Pseudomorphosis. Russian Revolution. Technicism. Christianities. North-American.

Este artigo foi encontrado no Arquivo Edgar Leuenroth, da Universidade Estadual de Campinas (UNICAMP), pela professora Doris Accioly e Silva, em 1999, que também lhe acrescentou resumo, palavras-chave e notas. 
Parte I (Folha Socialista, 5 abr. 1954, p. 6)

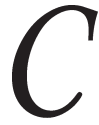

orresponde a uma exigência do conhecimento político atual a análise das forças que determinam a tensão mundial - Rússia e EEUU - como ponto de partida para uma visão objetiva dos problemas equacionados pela realidade.

Pomos de lado calmamente todos os slogans comunistas ou americanos na propaganda política, seja a defesa da pátria socialista ou a da civilização ocidental, e recorremos à única ciência, a História (Marx), para dela tirarmos os elementos que nos capacitarão a uma visão justa dos problemas do mundo moderno, dividido entre o imperialismo russo e o norte-americano, tendo como incógnitas a Alemanha e os movimentos coloniais.

Aprendemos com Marx a analisar um regime não pelo seu aspecto formal, lei escrita, assim como no caso dos regimes democráticos, que são liberais e humanistas no papel e na realidade praticam a violência na vida social, seja o linchamento de negros, repressão pesada às greves ou a política colonial, que em nada honra nossa civilização ocidental. E, por outro lado, correspondia a uma finalidade humana o regime instaurado nas zonas de dominação anarco-sindicalista na guerra civil da Espanha, embora ele abertamente recorresse à violência contra os fascistas, pois a violência ali estava a serviço da libertação do homem, enquanto a violência não admitida em lei, mas existente em regimes democráticos, está a serviço das forças que alienam o homem, na exploração de seu trabalho (burguesia), de sua liberdade (Estado) e de sua ideologia (religião).

Assim, a análise dos elementos constitutivos desse mundo chamado Rússia Soviética implica numa volta à história antiga e no seu entrelaçamento com a idade moderna russa - a Revolução Russa ou o bolchevismo.

\section{Pseudo-morfose}

Numa rocha estão encravados cristais de um mineral. Produzemse aberturas. Cai água que vai lavando os cristais de tal forma que só ficam suas cavidades; mais tarde, sobrevêm fenômenos vulcânicos que rompem a montanha, massas incandescentes se precipitam ao seu interior, se solidificam, cristalizando-se por sua vez, mas não em sua forma 
própria, têm que preencher as formas que aquelas cavidades lhes oferecem, assim resultam formas híbridas, cristais cuja estrutura interior difere da construção externa, espécies minerais que tomam formas alheias: os mineralogistas chamam isso de pseudo-morfose (pseudo-forma).

As pseudo-morfoses históricas dão-se quando uma cultura estranha cai sobre outra com tanta força que a cultura jovem não consegue respirar livremente, não chegando a constituir-se nas suas formas expressivas e peculiares, com consciência de seu papel histórico; nesse sentido, deu-se a conquista Aria nas índias, a do imperialismo assírio Tiglath-Pilesher ${ }^{1}$ sobre Israel, ou de Cortez no Peru; esmagaram as culturas existentes impedindo sua tomada de consciência, que se deu nas formas híbridas estabelecidas pela estrutura de dominação dos conquistadores (constituição de um Estado dos dominadores sobre os subjugados, ou uma burocracia de funcionários composta dos subjugados, mas controlada pelos vencedores com o fim fiscal etc. etc.). Existem ainda pseudo-morfoses ideológicas, que se dão quando uma ideologia ou religião formada dentro de uma constelação cultural determinada é levada para as formas desse mundo novo: é esse, por exemplo, o caso do cristianismo, tipo ideal da pseudo-morfose ideológica.

A pseudo-morfose no cristianismo manifesta-se expressivamente no mito do nascimento de Jesus. Sobre isso, em torno do qual seus discípulos nada sabem, formou-se uma lenda infantil. Ela tem suas raízes nos Apocalipses dos Antigos Persas e no Saoshyant, onde o Salvador dos últimos dias deveria nascer de uma virgem, isso nos marcos do cristianismo oriental. Mas para o cristianismo em sua fase de ocidentalização, isso significou coisa bem diferente. Assim, no Ocidente, junto a Jesus filho e muito acima dele, aparece a figura da Mãe de Deus, a Deusa-Mãe sobrepujando as Virgens-Mães do sincretismo: Isis, Cibele e Deméter. Mas Maria, a engendradora, a Mãe de Deus, constitui um grande escândalo para os cristãos orientais, ainda parecenos hoje ouvir as vozes dos monofisistas clamarem nas ruas de Éfeso contra isso. E as proposições dogmáticas advindas do culto à Virgem Maria determinaram, em última análise, a ocasião para que os monofisistas e os nestorianos ${ }^{2}$ se separassem da Igreja ocidental, estabelecendo uma pura religião de Jesus. Quando o Ocidente desperta, sentindo necessidade de um símbolo que exprimisse seu sentimento íntimo da história, do tempo infinito, teve que colocar no centro do cristianismo germano-gótico-católico a MATER DOLOROSA e não o SALVADOR 
Rússia atual: produto da herança bizantina e do espírito técnico norte-americano

DOEnTE. Ainda hoje, na Igreja Católica, Jesus ocupa o segundo lugar após a Madona.

Assim, a denominação de Messias (Christus) é judia; e Salvador e Senhor vêm da religiāo oriental aramaica. Na ocidentalização do cristianismo - pseudo-morfose - Christus se converte no nome de Salvador, no título de Jesus. Mas Senhor e Salvador já eram os títulos do culto helenístico ao Imperador. Esse é o sentido do processo de pseudo-morfose do cristianismo na sua ocidentalização. Assim, não existe cristianismo, mas cristianismos: o cristianismo primitivo oriental, o cristianismo da pseudo-morfose de Constantino o Grande, o cristianismo gótico e o cristianismo tipicamente ocidental, ativo, corporificado na Milícia Christi de Santo Inácio de Loyola.

Assim, o bolchevismo também é um produto de pseudo-morfose: a tradição bizantina e o espírito técnico americano constituem a estrutura íntima do Estado russo atual. A diferença primitiva entre a Rússia e o Ocidente mostra-se quando penetramos nas lendas das bilinas, que chegam ao auge no quadro das lendas de Kiev, do príncipe Wladimir e sua Távola Redonda e o herói popular Ylia de Morum. ${ }^{3}$ A diferença entre a Rússia e o Ocidente mostra-se nesses cantares, que correspondem ao Rei Arthur e aos Nibelungos.

Durante quase mil anos, a Rússia não pertenceu à civilização ocidental, senão, à civilização bizantina. Uma sociedade diferente, como a ocidental, da greco-romana, mas, por seu turno, com aspectos distintos. Os russos adotaram o cristianismo ortodoxo oriental bizantino nos fins do século $\mathrm{x}$ e depois da captura de Constantinopla pelos turcos em 1453 e a extinção do último vestígio do Império Romano do Oriente, o principado de Moscou, que se havia convertido no centro do reagrupamento da cristandade ortodoxa russa contra os muçulmanos e latinos, tomou dos gregos a herança bizantina. Em 1547, Ivan, o Terrível, coroou-se Tzar, o Imperador Romano do Oriente. Desde 1453, a Rússia foi o único país cristão ortodoxo de importância que não havia caído sob o domínio muçulmano; a captura de Constantinopla pelos turcos foi vingada por Ivan, o Terrível, quando, um século depois, arrancou Kazan das mãos dos tártaros. Era esse mais um passo na captação da herança bizantina pela Rússia. Essa política revela-se numa carta dirigida ao grão-duque Basílio III de Moscou pelo Monge Teófilo de Poskov: "A Igreja da velha Roma caiu por causa de sua heresia, as 
portas da Segunda Roma foram destruídas pelos turcos e infiéis; mas a Igreja de Moscou, a igreja da Nova Roma brilha mais resplandecente de que o sol em todo o universo: duas Romas caíram, mas a terceira se mantém firme, e não pode haver uma quarta". Sob a foice e o martelo, como sob a cruz, a Rússia é a "Santa Rússia" e Moscou é a Terceira Roma. Nesse sentido, opera a política do governo russo ao conferir liberdade ao clero russo - durante a Segunda Guerra - controlada pelo poder secular. Tal como no Estado bizantino, a Igreja pode ser cristã ou marxista, contanto que aceite ser instrumento do poder secular. Daí a razão dos discursos patrióticos do patriarca Sérgio, conclamando o povo a defender a "Santa Rússia", a causa "sagrada", contra o Invasor. O primeiro aspecto da tradição bizantina que permanece na Rússia atual é o papel influente da Igreja Ortodoxa sob o controle estatal. O segundo é a herança do Estado totalitário dirigido por um chefe carismático. O Estado totalitário bizantino da Idade Média ressuscita em Constantinopla o Império Romano. As contribuições mais sérias da civilização atualizam-se aí, onde não chega o poder do Estado Romano do Oriente, como o provam a construção da "Magna Grécia" na Calábria, com os cristãos gregos refugiados, ou o aparecimento do gênio cretense do século XV, Theotocopoulos, que admiramos sob o nome de EL GRECO. Os russos acreditavam que só poderiam sobreviver concentrando poder político na forma de Estado, este sim uma versão do Estado bizantino. O Grão Ducado de Moscou foi o laboratório para essa experiência política e o serviço prestado por Moscou - e sua recompensa - foi a consolidação, sob sua direção, de uma união de débeis principados numa potência unificada. Esse edifício estatal totalitário moscovita teve sua fachada mudada duas vezes - sob Pedro, O Grande, e sob Lenine, mas a essência de sua estrutura conservou-se inalterada e a União Soviética de hoje, como o Grão Ducado de Moscou do século XIV, reproduz os traços mais salientes do Império Romano do Oriente Medieval.

\section{Parte II (Folha Socialista, $1^{\circ}$ de junho de 1954, p. 2)}

$\mathrm{O}$ segundo aspecto que caracteriza o bolchevismo como produto de uma pseudo-morfose, além da herança bizantina, é a captação da técnica ocidental, mais precisamente, do espírito técnico norte-americano. É assim que Chicago é cantada em verso por Maiacowsky: ${ }^{4}$ 
Cidade

Erguida sobre um parafuso!

Cidade! Eletro-dinamo-mecânica, cidade!

Espiralóide

Sobre um gigantesco disco de bom aço

Agirá sobre si mesmo

Com cada martelada das horas

5000 arranha-céus

Sóis de granito

As praças:

A quilômetros de altura nos céus galopam

Formigantes de milhôes de criaturas

Broadways suspensas

Em cacho de aço tramadas

Na ponta dos postes

Coloca-se crepitando a luz elétrica

Cartazes de fumaça pelos ares

Inscrições fosforescentes

(Em: Espírito e Fisionomia do Bolchevismo, de René P. Miller, ed. Globo, p. 37-38).

Não só Chicago é alvo de entusiásticos cantos, como o ritmo de vida americana aparece como protótipo digno de imitação: - "Tomemos a torrente da revolução na Rússia Soviética. Sincronizemo-la com o ritmo do pulso da vida americana e executemos o nosso trabalho como um cronômetro" (Apelo de Gastieff para a mecanização) - obra citada, página 38.

A pseudo-morfose, 'a torrente da revolução' sincronizada com o ritmo do pulso da vida americana predispõe à formação de um tipo humano com essas características. É o que se deu.

Sosnovsky, o "literato da corte bolchevique", já nos primeiros anos da Revolução, fizera a proposta que se educassem os russos como se fossem americanos: "trata-se antes de mais nada [escreveu ele] de procurar encontrar novos homens que nós chamaremos russos-americanos e cabe ao Partido e ao Soviets dar ajuda no sentido de que esses homens sejam colocados no devido lugar e cuidar de que os patetas 
não os boicotem logo nos primeiros passos. Apenas durante os primeiros passos, pois no curso futuro de sua atividade esses 'americanos' já saberão se defender por si mesmos e liquidar os patetas. Os nossos 'americanos' devem ser postos sob a proteção do povo inteiro, é necessário que se os moldem em uma corte e que se obrigue todos os outros que sigam a direção deles". No ano de 1923 o novo Partido exige a organização dos "russos-americanos" para os quais não se exige de maneira alguma a estadia na América do Norte, que declarará guerra sem quartel aos batalhões russos. "Infelizmente nas minhas veias circula pouco sangue americano, mas sinto com todo o meu ser a aproximação dessa nova raça de homens e ponho a minha pena a serviço dela". Assim, a Revolução Russa não significa somente a apropriação da técnica ocidental mas do espírito dela, como foi forjado nos Estados Unidos. Tanto Rússia como EEUU não tiveram humanismo nem renascimento, logicamente o conjunto de fatores, as "coincidências culturais" (Marx) que se deram na Europa com o humanismo e o renascimento determinaram a formação de valores básicos na forma de vida dos europeus que não se deram no caso da Rússia e EEUU, onde vive-se para a produção. Daí advém que a Rússia não só cantou a técnica ocidental, mas também o estilo de vida americano, onde os valores humanistas europeus são substituídos pelos elementos puramente técnico-mecânicos na vida. Essa captação não é somente na cultura, mas incorpora-se no corpo doutrinário do leninismo-stalinismo, versão bizantina do marxismo.

"O leninismo é uma escola teórica e prática que forma um tipo especial de militante do Partido e do Estado, que cria um estilo especial leninista no trabalho. No que consistem os traços característicos deste estilo? Quais são as suas particularidades? Suas particularidades são: a) o impulso revolucionário russo; b) o espírito prático norte-americano. O estilo de leninismo consiste na reunião dessas duas particularidades" (em: Stalin - Os fundamentos do leninismo, p. 173, ed. Assunção). Tal como Chicago é cantada em verso por Maiacowsky, o espírito prático norte-americano o é também por Stálin: "O sentido prático norte-americano é a força indomável que não conhece nem reconhece barreiras, que com sua insistência e sua tenacidade destrói os obstáculos, embora pouco importantes, suscetíveis de dificultar a conclusão da tarefa iniciada e sem o que não é concebível um trabalho sério qualquer" (obra citada, p. 174). Em síntese, o bolchevismo, segundo Stálin, aparece assim definido: "A ciência do leninismo no trabalho 
do Partido e do Estado consiste na união do impulso revolucionário russo com o sentido prático norte-americano".

Assim como a Rússia de Moscou dos grandes boiardos e patriarcas leva a Rússia a verter-se nas formas alheias do alto barroco da Ilustração do século XVIII (1703), o bolchevismo leva a Rússia a tomar consciência do seu passado, atualizando a herança bizantina do Estado totalitário e do líder carismático (Lenine ou Stalin) e a tomar consciência de seu presente e futuro, adotando a técnica ocidental e seu espírito, na versão norte-americana. Daí a escolha entre dois mundos: Rússia ou Estados Unidos, ser um falso problema, não há o que escolher, eles como opostos se completam e identificam. Assim como a Rússia se ocidentalizou com a técnica (Revolução Russa), os EEUU se totalizaram pelo aparecimento de tendências totalitárias em seu seio (MacCarthy, M. Carram).

Perguntam os senhores: e a "revolução socialista" de 1917, onde ficou? A isso respondemos dizendo que a Revolução Russa no seu mecanismo econômico foi uma revolução industrial, que, pelo fato de dar-se em um país sem tradição burguesa ocidental e na decadência do capitalismo liberal, foi levada a cabo pela burocracia estatal dentro dos quadros do capitalismo de Estado. Por dar-se na decadência do capitalismo liberal teve a intenção subjetiva socialista esmagada, com o sufocamento da "Oposição Operária", da revolta dos Marinheiros de Cronstadt, onde se deu a passagem das fábricas da mão dos operários e seus Comitês para as mãos dos dirigentes nomeados por Lenine e Trotsky, e onde os Soviets foram atados à organização na qual a burocracia estava mais forte no Partido bolchevista. Assim, o apoio social proletário que mantinha a Revolução Russa foi substituído pela dominação burocrática dos funcionários do Partido, no Estado, nos Sindicatos e nas fábricas. Assim, hoje em dia, existe na Rússia capitalismo burocrático sem existir burguesia no sentido ocidental. Ele é a síntese lógica de dois processos: da herança da tradição estatal totalitária de Bizâncio com a assimilaçăo da técnica ocidental e do estilo de vida norte-americano, sob a direção de uma burocracia capitalista. Isso nos leva a definir o bolchevismo como um produto de pseudo-morfose.

\section{Notas}

1. Tiglat-Pilesher III ou Teglatefalasar III (746 a.C.-727 a.C.), imperador assírio que conquistou a Babilônia. 
2. Os Nestorianos, no século v, eram seguidores de Nestorius, bispo de Constantinopla. Acreditavam que Cristo reunia em si duas naturezas: uma divina e outra humana. Negavam a divindade de Maria, alegando que ela era mãe do Cristo homem e não do Deus. Os monofisistas, também do século $\mathrm{v}$, opunham-se aos nestorianos, afirmando a natureza una de Cristo.

3. O nome desse herói é Ilya Muromets, cuja grafia aparece diferente nesse artigo e que é ligado às Bilinas. Estas são narrativas orais épicas, que surgem a partir do século XI e focalizam de modo especial o período de Kiev, no qual se deu a ligação do Estado Russo com a religião cristã ortodoxa.

4. Respeitou-se a grafia dada pelo autor no texto original encontrado no jornal.

Disponível em <http://www.cedes.unicamp.br> 